\section{Exophthalmos of patients with Graves' disease in Chinese of Taiwan}

C-C Tsai ${ }^{1,2,3}, \mathrm{H}-\mathrm{C} \mathrm{Kau}{ }^{2,4}, \mathrm{~S}-\mathrm{C} \mathrm{Kao}{ }^{1,2}$

and $\mathrm{W}-\mathrm{M} \mathrm{Hsu}{ }^{1,2}$

Keywords: exophthalmos; Graves' disease;

Hertel's exophthalmometry

Purpose To determine the exophthalmos measurements in patients with Graves' disease (GD) and to compare with those of normal subjects among the Chinese of Taiwan.

Methods Hertel's exophthalmometry were performed in 163 consecutive adult GD patients and 419 normal subjects. The values of exophthalmos, asymmetry, and the distance between lateral orbital rims (base) were evaluated.

Results There was a significant difference between GD and normal adults for exophthalmos and asymmetry, with GD patients demonstrating a mean exophthalmos of $\mathbf{1 8 . 3 2} \mathrm{mm}$ and asymmetry of $0.93 \mathrm{~mm}$ as compared with 13.91 and $0.55 \mathrm{~mm}$ for normal subjects $(P<0.001)$. The mean value of base for GD adults $(106.52 \mathrm{~mm})$ is slightly greater than normal subjects $(\mathbf{1 0 5 . 8 2} \mathrm{mm})$. There was no gender difference in exophthalmometric value or asymmetry in each group. A total of 79 (48.5\%) GD patients had exophthalmos greater than the upper limit of normal Chinese in Taiwan (18.6 mm). Asymmetry over $2 \mathrm{~mm}$ was observed in $11(6.7 \%)$ patients with GD but in none of the normal subjects.

Conclusions GD patients have significant exophthalmos and asymmetry compared to normal subjects. In comparison with previous studies, exophthalmos values for Chinese in Taiwan tend to be lower than those of Caucasians and black-American people, but are close to those of Korean, Japanese, Iranian, Indian, and Asian-American people. Adequate adjustment of normal and abnormal values of exophthalmos according to individual differences is important for the diagnosis of orbital morbidity and management of thyroid associated orbitopathy.

Eye (2006) 20, 569-573. doi:10.1038/sj.eye.6701925; published online 20 May 2005
Introduction

Racial differences regarding eyeball position are important to clinical assessment and treatment of exophthalmos patients who have experienced trauma or may have possible inflammatory, infectious, vascular, neoplastic, autoimmune or congenital diseases. In adults, thyroid associated orbitopathy (TAO) is the most common cause of unilateral or bilateral exophthalmos. The differences in normal or Graves' disease (GD) exophthalmos for both black and white populations have been well described, ${ }^{1-6}$ but the ethnic difference especially in the Chinese has rarely been recognized in English literature. In this study, we compare the exophthalmos of GD adult patients with those of normal subjects among the Chinese of Taiwan, and also review the published papers to compare such ophthalmic differences between various racial and ethnic groups.

\section{Materials and methods}

Between January 2002 and May 2004, 163 consecutive patients (61 male and 102 female) with GD, and 419 randomly selected normal, healthy subjects (188 male and 231 female) seen at the eye clinic of Taipei Veterans General Hospital were included in this study. GD group includes all GD patients either with or without ophthalmopathy. Most of the Chinese in Taiwan emigrated from Mainland China. The diagnosis of GD was established by experienced endocrinologists on the basis of the following criteria: (1) diffuse goiter; (2) hyperthyroid symptoms and signs; (3) increased serum thyroid hormone levels; (4) suppressed serum TSH levels; (5) increased ${ }^{99 m}$ Tc thyroid uptake;
${ }^{1}$ Department of Ophthalmology, Taipei Veterans General Hospital Taiwan

${ }^{2}$ Department of Ophthalmology, School of Medicine, National YangMing University, Taiwan

${ }^{3}$ Institute of Clinical Medicine, National YangMing University, Taiwan

${ }^{4}$ Department of Ophthalmology, Taoyuan Veterans Hospital, Taiwan

Correspondence: C-C Tsai, Department of Ophthalmology, Taipei Veterans General Hospital, No. 201, Sec. 2, Shih-Pai Road, Taipei, Taiwan, ROC E-mail: cctsai1234@ yahoo.com

Received: 17 January 2005 Accepted in revised form: 22 March 2005 Published online: 20 May 2005

No public and private supports.

None of the authors have any commercial interest in the materials mentioned herein. 
and (6) measurable circulating levels of antithyroid antibodies. All subjects with other causes of exophthalmos (eg, orbital tumours, inflammation, vascular disorders, trauma, postsurgery, etc.) were excluded. Computed tomography was used to confirm the cause of exophthalmos if necessary. Also excluded were those with high myopia or hyperopia more than 6 diopters equivalent sphere, since very short or long axial length might influence the exophthalmometry reading. None of the normal subjects had symptoms and signs of GD or euthyroid orbitopathy.

Eligible subjects underwent exophthalmometric assessment by the same physician (CCT) using one accurately calibrated Hertel exophthalmometer (Keeler Instruments Inc., Broomall, PA, USA). There have been many exophthalmometer designs and modifications suggested in the literature. Of these, the Hertel exophthalmometer is still the most widely used instrument for measuring exophthalmos; although several limitations have been identified in its use. ${ }^{7-9}$ Protrusion of eyeball, difference of both eyes' protrusion (asymmetry), and the distance between lateral orbital rims (base) were recorded. The study was as proved by the institutional review board. Informed consent was obtained from all subjects.

\section{Statistical analysis}

Data are expressed as the mean $\pm S D$ (standard deviation). Statistical significance was determined by independent samples $t$-test and $\chi^{2}$-test (gender between groups) using SPSS 11.0 for Windows (SPSS Inc.).

\section{Results}

The mean age of patients with GD was 45.5 years (range, 20-89 years). The mean age of normal was 53.7 years (range, 18-90 years). There is no significant gender difference between two groups $(P=0.062)$. Among the GD patients, the mean values of exophthalmos, asymmetry on protrusion, and base were 18.08, 0.86 , and $106.64 \mathrm{~mm}$, respectively, in male subjects and 18.47, 0.97, and $106.44 \mathrm{~mm}$, respectively, in female subjects (Table 1). For the normal subjects, the mean values of exophthalmos, asymmetry on protrusion, and base were 13.97, 0.54, and $106.45 \mathrm{~mm}$, respectively in male subjects and 13.86, 0.56, and $105.31 \mathrm{~mm}$, respectively in female subjects (Table 2). No apparent difference was observed on exophthalmometric value between right and left eyes in each group. There was no significant difference in the exophthalmometric value or asymmetry on comparing sexes within each group. However, the mean value of base for normal male subjects is greater than female $(P=0.002)$.

Figure 1 demonstrates the distribution of exophthalmos in GD patients and normal subjects. There was a significant difference of exophthalmometric reading between GD patients and normal subjects $(P<0.001)$.The mean value of base for GD patients $(106.52 \mathrm{~mm})$ was slightly higher than that of normal subjects (105.82 mm, $P=0.028$ ) (Table 3 ). Figure 2 showed comparison of GD patients with normal subjects on asymmetric protrusion between both eyes. A significant difference was also found between both groups for mean asymmetry (Table 3), with 385 (92\%) normal subjects showing asymmetry of $\leqslant 1 \mathrm{~mm}$ compared with $116(71 \%)$ for GD patients. None of the normal subjects has significant asymmetry $>2 \mathrm{~mm}$.

Table 1 Exophthalmometric, asymmetric, and base values in 163 adults with GD

\begin{tabular}{|c|c|c|c|c|c|c|c|c|c|c|c|c|}
\hline & Number & Age (years) & $O D(m m$, range $)$ & $\mathrm{P}$ & OS ( $m m$, range) & $\mathrm{P}$ & $\mathrm{OU}(\mathrm{mm})$ & $\mathrm{P}$ & $\begin{array}{l}\text { Asymmetry } \\
(\mathrm{mm})\end{array}$ & $\mathrm{P}$ & Base $(\mathrm{mm})$ & $\mathrm{P}$ \\
\hline Male & 61 & $52.51 \pm 14.81$ & $\begin{array}{c}18.18 \pm 3.51 \\
(11-26)\end{array}$ & 0.957 & $\begin{array}{c}17.98 \pm 3.70 \\
(11-28)\end{array}$ & 0.180 & $18.08 \pm 3.50$ & 0.516 & 0.86 & 0.379 & $106.64 \pm 2.75$ & 0.684 \\
\hline Female & 102 & $41.26 \pm 12.66$ & $\begin{array}{c}18.15 \pm 3.93 \\
(8-29)\end{array}$ & & $\begin{array}{c}18.78 \pm 3.65 \\
(11-28)\end{array}$ & & $18.47 \pm 3.72$ & & 0.97 & & $106.44 \pm 3.15$ & \\
\hline
\end{tabular}

Table 2 Exophthalmometric, asymmetric, and base values in 419 normal adults

\begin{tabular}{|c|c|c|c|c|c|c|c|c|c|c|c|c|}
\hline & Number & Age (years) & $O D(m m$, range $)$ & $\mathrm{P}$ & OS (mm, range) & $\mathrm{P}$ & $O U(m m)$ & $\mathrm{P}$ & $\begin{array}{c}\text { Asymmetry } \\
(\mathrm{mm})\end{array}$ & $\mathrm{P}$ & Base (mm) & $\mathrm{P}$ \\
\hline Male & 188 & $59.43 \pm 19.51$ & $\begin{array}{c}13.97 \pm 2.23 \\
(8-20)\end{array}$ & 0.525 & $\begin{array}{c}13.98 \pm 2.37 \\
(8-20.5)\end{array}$ & 0.732 & $13.97 \pm 2.26$ & 0.620 & 0.54 & 0.788 & $106.45 \pm 4.12$ & $0.007^{\mathrm{a}}$ \\
\hline Female & 231 & $49.01 \pm 19.07$ & $\begin{array}{c}13.86 \pm 2.46 \\
(7-21)\end{array}$ & & $\begin{array}{c}13.90 \pm 2.38 \\
(8-20.5)\end{array}$ & & $13.86 \pm 2.39$ & & 0.56 & & $105.31 \pm 4.36$ & \\
\hline
\end{tabular}

${ }^{\mathrm{a}} \mathrm{P}<0.05$. 


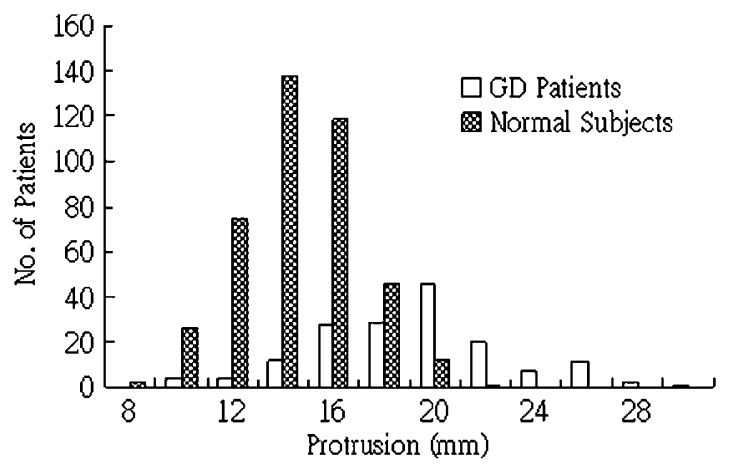

Figure 1 Distribution of eyeball protrusion for GD patients and normal subjects

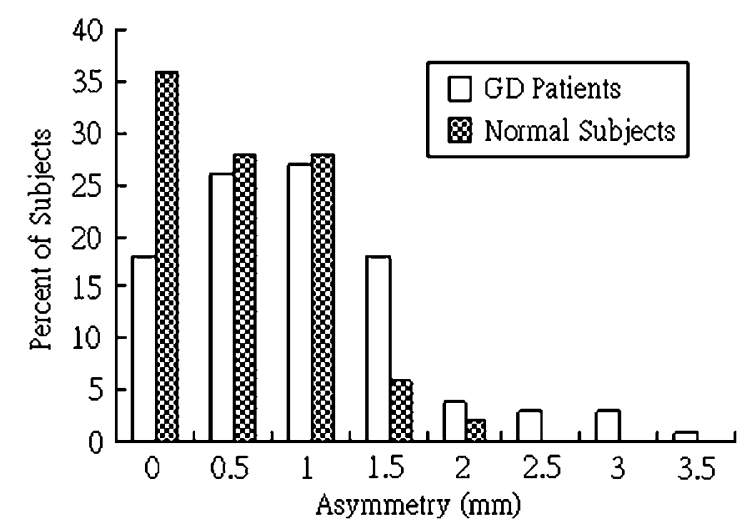

Figure 2 Distribution of asymmetry of protrusion for GD patients and normal subjects.

Table 3 Comparison of exophthalmometric, asymmetric, and base values between normal and GD adults

\begin{tabular}{|c|c|c|c|c|c|c|}
\hline & $\begin{array}{l}\text { Average exophthalmos } \\
\qquad(\mathrm{mm})\end{array}$ & $\mathrm{P}$ & $\begin{array}{c}\text { Average asymmetry } \\
(\mathrm{mm})\end{array}$ & $\mathrm{P}$ & Base & $\mathrm{P}$ \\
\hline Normal subjects & $13.91 \pm 2.33$ & $<0.001^{\mathrm{a}}$ & 0.55 & $<0.001^{\mathrm{a}}$ & $105.82 \pm 4.29$ & $0.028^{\mathrm{a}}$ \\
\hline Graves patients & $18.32 \pm 3.64$ & & 0.93 & & $106.52 \pm 3.00$ & \\
\hline
\end{tabular}

${ }^{\mathrm{a}} P<0.05$

\section{Discussions}

Proptosis, defined as measured exophthalmos greater than $2 \mathrm{~mm}$ above the normal upper limit, may result from endocrine disease, neoplasm, inflammation, infection, trauma, vascular disorder, and miscellaneous cause such as obesity or high myopia. ${ }^{10,11}$ Graves exophthalmos (GO), the most common cause of proptosis in adults, occurs in 30 to $70 \%$ of patients with GO. ${ }^{12,13}$ This predominant anatomical change in GO can be explained on a mechanical basis by an increase in the volume of both the orbital fatty connective tissues and the extraocular muscle bodies. ${ }^{14}$ It remains likely that both the accumulation of glycosaminoglycans and the expansion of the connective/adipose tissues contribute to the increase in orbital tissue volume characteristic of GO. ${ }^{15}$ Marked exophthalmos may cause secondary exposure keratitis and lead to corneal ulceration or perforation. Therefore, apart from optic neuropathy, the presence of decreased visual acuity attributable to severe exophthalmos can define the ophthalmopathy as severe, and the change of exophthalmos may indicate a progression of the GO. ${ }^{16}$

The identification of exophthalmos relies not only on accurate measurements but also on normal reference limits. Establishing a range of normal values is important in diagnosing and managing orbital abnormalities related to eyeball protrusion. In comparison with previous studies of normal subjects among different populations, the normal exophthalmos value for the Chinese in Taiwan obtained from our study seemed to be lower than that of both black and white people in the United States, ${ }^{3-6}$ Danish, ${ }^{1,2}$ and Mexican; ${ }^{17}$ but is close to that of Indian, ${ }^{18}$ Korean, ${ }^{19}$ and Japan. ${ }^{20}$ If the upper normal limit was defined as 2 standard deviations above the mean, the upper limit of normal Chinese in our study was $18.6 \mathrm{~mm}$, which was lower than $21 \mathrm{~mm}$ that has traditionally been considered for Caucasians. Migliori and Gladstone ${ }^{4}$ reported the upper limit of normal value was $20.1 \mathrm{~mm}$ for white women, $21.7 \mathrm{~mm}$ for white men, $23.0 \mathrm{~mm}$ for black women, and $24.7 \mathrm{~mm}$ for black men, which all were so different from what has been reported of the others $17.7 \mathrm{~mm}$ for the Japanese, ${ }^{20} 18.3 \mathrm{~mm}$ for Koreans, ${ }^{19} 19.3 \mathrm{~mm}$ for Iranians, ${ }^{21}$ and $18.6 \mathrm{~mm}$ for the present study. The clinical significance is that an Asian patient with exophthalmometric reading within the upper normal limit of Caucasian measurements may consider advanced study to exclude TAO or other cause of exophthalmos. Sex difference does exist in some studies, especially in black and white Americans, ${ }^{3,4}$ but not in our study. The distance between lateral orbital rims in the present study $(106.45 \pm 4.12 \mathrm{~mm}$ in male; $105.31 \pm 4.36 \mathrm{~mm}$ in female) was greater than those of Caucasian $(98.39 \pm 3.86 \mathrm{~mm}$ in male; $95.41 \pm 3.83 \mathrm{~mm}$ in 
female $)^{4}$ and black-Americans $(98.86 \pm 3.57 \mathrm{~mm}$ in male; $95.70 \pm 3.44 \mathrm{~mm}$ in female) ${ }_{1}^{5}$ but is similar to that study of Iran $(106.3 \pm 5.2 \mathrm{~mm}) .{ }^{21}$ Borgren et $a l^{22}$ found eye position is correlated with skull size and race by using radiographic exophthalmometry. Orientals are thought to have a rounder and shallow orbit, black people have a rectangular orbit, and white people are in between. The anthropological difference may explain the wide variation of exophthalmos and base value between different population groups.

Exophthalmos is common among patients with Graves' eye disease (GED). Frueh et $a l^{23}$ found that the mean exophthalmometer reading was significantly greater in patients with GED than in normal subjects; however, there were no expected gender and age effects on the exophthalmometer reading among GED patients. In the present study, we found that exophthalmos is also common among patients with GD. Significant exophthalmos, over the upper limit of normal Chinese in Taiwan $(18.6 \mathrm{~mm})$, was observed in $79(48.5 \%)$ patients with GD. Amino also reported that the mean values for protrusion in patients with thyrotoxic GD $(16.6 \pm 2.1 \mathrm{~mm})$ were greater than in healthy subjects $(14.2 \pm 1.8 \mathrm{~mm}) .^{20}$ The distribution pattern of exophthalmos in our GD adults was similar to normal population but just shifted to higher values. This is in agreement with other previous studies. $^{20,11}$

Diagnosis of the eye disease as GO is difficult in unilateral exophthalmos, particularly if they are in an euthyroid state. However, GO is still the most important differential diagnosis in adult patients with unilateral exophthalmos. The present study demonstrates a higher mean asymmetry $(0.93 \mathrm{~mm})$ in GD patients than in normal subjects. The mean values of asymmetry for normal subjects among different population groups are between 0.35 and $0.56 \mathrm{~mm} .{ }^{4,5}$ Soroudi et $\mathrm{l}^{24}$ found that 9\% patients with thyroid-related orbitopathy had asymmetric proptosis with a difference of $\geqslant 2 \mathrm{~mm}$. Our study also showed that $6.7 \%$ patients with GD had asymmetric exophthalmos $>2 \mathrm{~mm}$, and $11.0 \% \geqslant 2 \mathrm{~mm}$, compared with $0 \%$ and $1.9 \%$ in normal subjects. It appears that patients with exophthalmos $>2 \mathrm{~mm}$ were more likely due to pathological change and need additional examinations.

Based on the findings of the present study, the exophthalmometric values, asymmetry, and base values of the Chinese in Taiwan for GD patients and normal subjects are established. The normal position of the eyes in the orbit varies widely among different populations, especially between Caucasian, black-American, and Orientals. In general, the values of eyeball protrusion in Asians tend to be lower than those of Caucasians and black-Americans. By recognizing and adjusting such ethnic variations of ocular anatomy in clinical practice, physicians will be better able to differentiate between normal and abnormal orbital disease and to assess and manage thyroid associated orbitopathy.

\section{References}

1 Knudtzon K. On exophthalmometry: the result of 724 measurements with Hertel's exophthalmometer on normal adult individuals. Acta Psychiatr Neurol 1949; 24: 523-537.

2 Fledelius HC, Stubgaard M. Changes in eye position during growth and adult life. Acta Ophthalmol 1986; 64: 481-486.

3 De Juan E, Hurley DP, Sapira JD. Racial differences in normal values of proptosis. Arch Intern Med 1980; 140: 1230-1231.

4 Migliori ME, Gladstone GJ. Determination of the normal range of exophthalmometric values for black and white adults. Am J Ophthalmol 1984; 98: 438-442.

5 Dunsky IL. Normative data for Hertel's exophthalmometry in a normal adult black population. Optom Vis Sci 1992; 69: 562-564.

6 Barretto RL, Mathog RH. Orbital measurement in black and white populations. Laryngoscope 1999; 109: 1051-1054.

7 Sleep TJ, Manners RM. Interinstrument variability in Herteltype exophthalmometers. Ophthal Plast Reconstr Surg 2002; 18: 254-257.

8 O'Donnell NP, Virdi M, Kemp EG. Hertel exophthalmometry: the most appropriate measuring technique. Br J Ophthalmol 1999; 83: 1097.

9 Musch DC, Frueh BR, Landis JR. The reliability of Hertel exophthalmometry. Ophthalmology 1985; 92: 1177-1180.

10 Grove AS. Evaluation of exophthalmos. N Engl J Med 1975; 292: 1005-1013.

11 Smolders MH, Graniewski-Wijnands HS, Meinders AE, Fogteloo AJ, Pijl H, de Keizer RJ. Exophthalmos in obesity. Ophthalmic Res 2004; 36: 78-81.

12 Wiersinga WM, Smit T, van der Gaag R, Mourits M, Koornneef L. Clinical presentation of Graves' ophthalmopathy. Ophthalmic Res 1989; 21: 73-82.

13 Kahaly GJ, Bockmann H, Beyer J, Bischoff S. Longterm observation of endocrine ophthalmopathy and retrospective appraisal of therapeutic measures. J Endocrinol Invest 1990; 13: 287-292.

14 Bahn RS, Heufelder AE. Mechanisms of disease: pathogenesis of Graves' ophthalmopathy. N Engl J Med 1993; 329: 1468-1475.

15 Prabhakar BS, Bahn RS, Smith TJ. Current perspective on the pathogenesis of Graves' disease and ophthalmopathy. Endocr Rev 2003; 24: 802-835.

16 Bartalena L, Pinchera A, Marcocci C. Management of Graves' ophthalmopathy: reality and perspectives. Endocr Rev 2000; 21: 168-199.

17 Bolanos Gil de Montes F, Perez Resinas FM, Rodriguez Garcia M, Gonzalez Ortiz M. Exophthalmometry in Mexican adults. Rev Invest Clin 1999; 51: 341-343.

18 Sodhi PK, Gupta VP, Pandey RM. Exophthalmometric values in a normal Indian population. Orbit 2001; 20: 1-9.

19 Kim IT, Choi JB. Normal range of exophthalmos values on orbit computerized tomography in Koreans. Ophthalmologica 2001; 215: 156-162.

20 Amino N, Yuasa T, Yabu Y, Miyai K, Kumahara Y. Exophthalmos in autoimmune thyroid disease. J Clin Endocrinol Metab 1980; 51: 1232-1234. 
21 Kashkouli MB, Beigi B, Noorani MM, Nojoomi M. Hertel exophthalmometry: Reliability and interobserver variation. Orbit 2003; 22: 239-245.

22 Bogren HG, Schermer MJ, Franti C, Elfstrom G, Tengroth B. Radiographic exophthalmometry. Trans Am Acad Ophthalmol Otolaryngol 1976; 81: 298-304.
23 Frueh BR, Musch DC, Garber FW. Exophthalmometer readings in patients with Graves' eye disease. Ophthalmic Surg 1986; 17: 37-40.

24 Soroudi AE, Goldberg RA, McCann JD. Prevalence of asymmetric exophthalmos in Graves orbitopathy. Ophthal Plast Reconstr Surg 2004; 20: 224-225. 